\section{REFERENCES}

1. H. H. Wieder, J, Vac. Sci. Technol. A, 2, 97 (1984),

2. T. Oda and T. Sugano, Jpn. J. Appl. Phys., 15, 1317 (1976).

3. C. C. Chang, P. H. Citrin, and B. Schwortz, J. Vac. Sci. Technol., 14, 943 (1977).

4. I. Shiota, K. Motoya, T. Ohmi, N. Miyamoto, and J. Nishizawa, This Journal, 124, 155 (1977).

5. P. A. Bertrand, J. Vac. Sci. Technol., 18, 28 (1981)

6. D. E. Aspens and A. A. Studna, Appl. Phys. Lett., 39, 316 (1981).

7. J. L. Zilko and R. S. Williams, This Journal, 129, 406 (1982).

8. R. P. Vasquez, B. F. Lewis, and F. J. Grunthaner, Appl. Phys. Lett., 42, 293 (1983).

9. R. P. Vasquez, B. F. Lewis, and F. J. Grunthaner, J. Vac. Sci. Technol. B, 1, 791 (1983).

10. H. Iwasaki, Y. Mizokawa, R. Nishitani, and S. Nakamura, Jpn. J. Appl. Phys., 17, 1925 (1978).

11. H. Iwasaki, Y. Mizokawa, R. Nishitani, and S. Nakamura, ibid., 18, 1525 (1979).

12. H. F. Hsieh and H. C. Shih, J. Appl. Phys., 66, 3542 (1989).
13. H. F. Hsieh and H. C. Shih, This Journal, 137, 1348 (1990).

14. JCPDS cards, 5-601, 11-370, 15-778, 20-114, 22-1050, $29-665,30-100$.

15. JCPDS card, 12-398.

16. C. W. Wilmsen, "Physics and Chemistry of III-V Compound Semiconductor Interfaces," p. 406, Plenum Press, New York (1985).

17. Marcel Pourbaix, "Atlas of Electrochemical Equilibria in Aqueous Solutions," 2nd ed., NACE, Houston, TX (1974).

18. R. T. Sanderson, "Chemical Bonds and Bond Energy," Academic Press, Inc., New York (1976).

19. G. P. Schwartz, W. A. Sunder, and J. E. Griffiths, This Journal, 129, 1361 (1982).

20. H. Gerischer, Ber. Bunsenges. Phys. Chem., 69, 578 (1965).

21. H. Gerischer, This Journal, 113, 1174 (1966).

22. H. Gerischer and W. Mindt, Electrochim. Acta, 13, 1329 (1968).

23. H. Gerischer, Surf. Sci., 13, 265 (1969).

24. M. L. Wendell, "The Oxidation States of the Elements and Their Potentials in Aqueous Solutions," 2nd ed., Prentice-Hall, Englewood Cliffs, NJ (1953).

\title{
Deposition and Electrical Properties of Thin Porous Ceramic Electrode Layers for Solid Oxide Fuel Cell Application
}

\author{
L. G. J. de Haart, ${ }^{\star}$ R. A. Kuipers, K. J. de Vries, and A. J. Burggraaf \\ Laboratory of Inorganic Chemistry, Materials Science, and Catalysis, Department of Chemical Technology, University \\ of Twente, P.O. Box 217, 7500 AE Enschede, The Netherlands
}

ABSTRACT

The influence of the microstructure on the electrical properties and polarization behavior of thin porous ceramic electrode layers used in solid oxide fuel cells has been investigated. Thin layers $(2-10 \mu \mathrm{m})$ of the cathode material $\mathrm{Sr}_{0.15} \mathrm{La}_{0.85} \mathrm{MnO}_{3}$ (15SLM) were film coated on YSZ substrates from classified suspensions. Narrow particle-size distributions in the suspension resulted in close-packed layers with a very homogeneous porosity and pore-size distribution. The specific conductivity of the layers decreased significantly with increasing porosity and mean pore size. A specific conductivity of $109 \mathrm{~S} \cdot \mathrm{cm}^{-1}$ was obtained at $1000^{\circ} \mathrm{C}$ for a $2.9 \mu \mathrm{m}$ thick layer from a suspension with particles in the range 0.10 $0.25 \mu \mathrm{m}$. The current-overvoltage behavior of the film-coated layers presented in this study did not, however, show any significant dependence on the thickness and the microstructure of the porous layers. Overvoltages $(\eta)$ at a current density of $0.1 \mathrm{~A} / \mathrm{cm}^{2}$ at $898^{\circ} \mathrm{C}$ were quite low, i.e., in the range $60-70 \mathrm{mV}$. In comparison with other studies it is shown that film coating improves the microstructure of the ceramic electrode layers, which in turn lowers the cathodic overvoltages for the oxygen reduction reaction.

High-temperature fuel cells with zirconia electrolytes have been studied since 1937 (Bauer and Preis (1)). The real development of solid oxide fuel cells (SOFC), however, started in the early sixties. Since that time a variety of materials has been investigated for their use in SOFC systems, and there has been a gradual evolution of stack configurations.

The current status in the development of SOFC shows, that on a laboratory scale a small stack of cells can operate over several years without degradation. The materials preferably used for cathode and anode are Sr-doped $\mathrm{LaMnO}_{3}$ and $\mathrm{Ni}$-zirconia cermet, respectively. As interconnection material between adjacent cells $\mathrm{Mg}$-doped $\mathrm{LaCrO}_{3}$ is used. Several types of multi-cell systems have been proposed and some have been fabricated and tested $(2,3)$.

One of today's most developed SOFC stack designs is the tubular configuration introduced by Westinghouse around 1980 (2-4). Unfortunately this tubular SOFC design has the disadvantage of a long electron current path through the electrode layers. This causes, especially in the cathode layer, large ohmic voltage drops. The resistivity of the Sr-doped $\mathrm{LaMnO}_{3}$ layer is still too high for this type of configuration. The thickness of the cathode layer can be increased in order to decrease the ohmic resistance, but this can increase the concentration polarization losses arising from a reduced gaseous oxygen flux through the pores of the thick cathode layer.

* Electrochemical Society Active Member.
In the monolithic-type configuration first proposed by the Argonne National Laboratory $(2,5)$ and the planar configurations which recently have gained much more interest (6), the electron current path through the electrode layer is considerably shorter, thus substantially decreasing the ohmic polarization losses in these types of configurations. Unfortunately the low electrocatalytic activity of the Sr-doped $\mathrm{LaMnO}_{3}$ cathode material towards the oxygen reduction reaction still causes severe nonohmic polarization losses. This low electrocatalytic activity compels the existence of three-phase boundaries electrolyte/electrode/ gaseous oxygen for the oxygen reduction reaction to occur. That is, if a purely electronic conducting material is used, the cathode layer must have a certain porosity, which in turn affects the conductivity of the electrode layer.

Several perovskite-type materials have been tested as cathodes, in order to reduce the ohmic and/or nonohmic polarization losses $(7,8)$. The important role the morphology of the electrode layer, i.e., the porosity and the pore size distribution, plays both on the ohmic and on the nonohmic polarization losses, is however not considered in depth in the literature. Contradictory requirements have to be met. To avoid nonohmic polarization in high current application a large internal surface (small grains and thick layers) is favorable. To avoid polarization due to diffusional limitations in the gas phase, large pores and a thin layer are required. Ohmic polarization is lowered by a small porosity, very good and large intergrain contacts, 
and thick layers. So a compromise is necessary. Therefore we have investigated the influence of the morphology of thin porous ceramic electrode layers of the state-of-the-art cathode material $\mathrm{Sr}_{0.15} \mathrm{La}_{0.85} \mathrm{MnO}_{3}$ on their electrical properties and polarization behavior (9). This composition with a low Sr content was also chosen to exclude any effect on the polarization behavior due to an enhanced oxygen ion conductivity, which is observed for compositions with higher $\mathrm{Sr}$ contents $(\geq 0.3)$.

In this investigation our first goal is to prepare relatively thin $(1-5 \mu \mathrm{m})$ layers with relatively small grains with many contact points and a homogeneous particle and pore size distribution. A film coating technique was developed which offers a good control of the morphology of the deposited layer and of the fabrication reproducibility of thin electrode layers. This film coating technique is based on the use of processed suspensions of the cathode material powder. The influence of the particle-size distribution of the suspended powder on the morphology of the filmcoated layer was investigated. Suspensions with different particle-size distributions were obtained by classification of the powder, which is described in the first section of this paper.

\section{Cathode Material Processing}

Powder preparation.-The perovskite-type oxide with the composition $\mathrm{Sr}_{0.15} \mathrm{La}_{0.85} \mathrm{MnO}_{3}$ (15SLM) was prepared via a citrate synthesis route (10). Starting materials were: $\mathrm{SrCO}_{3}$ (Merck), La $\mathrm{O}_{3}$ (Fluka), $\mathrm{Mn}\left(\mathrm{NO}_{3}\right)_{2} \cdot 4 \mathrm{H}_{2} \mathrm{O}$ (Merck) and citric acid monohydrate (Merck). The $\mathrm{La}_{2} \mathrm{O}_{3}$ was fired at $1200^{\circ} \mathrm{C}$ for $12 \mathrm{~h}$ before use, to remove water and carbon dioxide. The $\mathrm{La}_{2} \mathrm{O}_{3}, \mathrm{SrCO}_{3}$ and manganese nitrate were in the desired ratio dissolved in concentrated nitric acid (Merck). Citric acid was added to this solution as complexing agent for the cations in such a ratio, that to each mole of metal ion, one mole of citric acid was present. The solution was then neutralized to a $\mathrm{pH}$ of $7-8$ by adding concentrated ammonia (Merck). During the addition of both the citric acid and the ammonia the solution was kept in an ice bath and constantly stirred.

The solution was subsequently heated in equal proportions of $100 \mathrm{ml}$ in an oversized Pyrex three-liter beaker on a hot plate. After evaporation of the water a viscous mass was formed, followed by a large swelling and finally spontaneous combustion (pyrolysis) started. The amorphous product formed filled the beaker completely. This product was collected and calcined for $16 \mathrm{~h}$ at $950^{\circ} \mathrm{C}$ in air in order to burn out all carbon rests remaining from the precursor. The calcined powder was finally milled in a satellite-type milling apparatus in a zirconia beaker for $2-3 \mathrm{~h}$, with isopropyl alcohol (Merck) or acetone (Merck) added as milling medium.

Powder characterization.-The XRD pattern obtained for the calcined powder $\mathrm{Sr}_{0.15} \mathrm{La}_{0.85} \mathrm{MnO}_{3}(15 \mathrm{SLM})$ was similar to the pattern reported for $\mathrm{Sr}_{0.1} \mathrm{La}_{0.9} \mathrm{MnO}_{3}$ by Hammouche et al. (11) and the one for $\mathrm{Sr}_{0.1} \mathrm{La}_{0.9} \mathrm{CoO}_{3}$ reported by Ohbayashi et al. (12). The pattern could be perfectly indexed in the hexagonal-rhombohedral system. Unit cell parameters calculated from these data are $a_{\mathrm{b}}=5.526 \AA$ and $c_{\mathrm{h}}=13.361 \AA$. These unit cell parameters agree very well with the observations of Hammouche et al. (11).

The composition of the calcined powder was analyzed with $\mathrm{XRF}$. The analysis showed the powder to have the composition 5.58 weight percent (w/o) Sr, 50.7 w/o La, and 23.5 w/o $\mathrm{Mn}$, i.e., $\mathrm{Sr}_{0.15} \mathrm{La}_{0.85} \mathrm{MnO}_{3-\delta}$.

The BET surface area $\left(S_{\mathrm{BET}}\right)$ of the calcined powder was determined by Ar gas adsorption measurements at $77 \mathrm{~K}$. For the calcined samples a BET surface area of $4.7 \mathrm{~m}^{2} / \mathrm{g}$ was determined. Assuming spherically shaped grains, a mean particle-size of $0.2 \mu \mathrm{m}$ can be calculated from $S_{\mathrm{BET}}$. This mean particle size was confirmed by SEM observations.

A 15SLM sample calcined for $16 \mathrm{~h}$ at $950^{\circ} \mathrm{C}$ was analyzed with a Stanton Redcroft Differential Scanning Calorimeter 1500 in a stream of nitrogen up to $1350^{\circ} \mathrm{C}$. No peaks could be observed in the DSC recording, i.e., no phase transitions in the material or decomposition occur up to this temperature. The sintering behavior of the powder was analyzed with a Netzsch 402 E dilatometer. The powder was first isostatically pressed at $400 \mathrm{MPa}$, resulting in a green density of $3.7 \mathrm{~g} / \mathrm{cm}^{3}$ ( $56 \%$ of the theoretical density). This green sample was then heated at $2 \%$ min to $1500^{\circ} \mathrm{C}$ in the dilatometer. The dimensional change of the sample as a function of the temperature showed that sintering of the material starts around $1200^{\circ} \mathrm{C}$, but densification occurs mostly in the range $1300-1350^{\circ} \mathrm{C}$ where the maximum in the densification rate is observed. The final density reached was $5.9 \mathrm{~g} / \mathrm{cm}^{3}$ ( $90 \%$ of the theoretical density).

Powder classification.-Preliminary film coating experiments using a suspension containing the as-obtained calcined powder, resulted in very inhomogeneous layers with a very poor mechanical stability, which was probably due to the very broad particle size distribution of the calcined powder and the presence of large agglomerates. In order to improve the homogeneity of the layers, suspensions of the calcined powder with different narrowed particle size distributions had to be used. The powder was therefore classified by centrifuging suspensions of the powder in isopropyl alcohol using a Sorvall SS-3 Automatic centrifuge. The time $t$ required for a spherical particle of diameter $d$ to move from an initial axial position $r_{0}$ to a final axial position $r$ is given by the corrected Stoke's law for sedimentation (13)

$$
t=\frac{18 \eta \ln \left(r / r_{0}\right)}{\left(\rho_{2}-\rho_{1}\right) \omega^{2} d^{2}(1-6.55 \phi)}
$$

where $\eta$ is the viscosity of the fluid, $\left(\rho_{2}-\rho_{1}\right)$ is the density difference between the particle and the fluid, $\omega$ is the angular velocity of the centrifuge and (1-6.55 $\phi$ ) is a correction factor derived by Batchelor to account for the nonideal behavior in concentrated suspensions (14). Here $\phi$ is the volume fraction of the suspension, which is typically around $6 \%$ in our case. For the several desired particle size ranges given in Table I and selected centrifuging speeds we estimated the times from Eq. [1], with $\eta=2.49 \mathrm{cP}$ (measured with a Contraves low shear 30 at $25^{\circ} \mathrm{C}$ ), $r=108 \mathrm{~mm}, r_{0}=$ $60 \mathrm{~mm}, \rho_{2}=5.68 \mathrm{~g} / \mathrm{cm}^{3}$ (measured with the Archimedes method), and $\rho_{1}=0.785 \mathrm{~g} / \mathrm{cm}^{3}$ (15). The estimated times and centrifuging speeds are also given in Table $I$.

The collected fractions were dried, weighed, and analyzed with SEM. The weight of the collected fractions and the results of the SEM analysis are given in Table I. The particle-size ranges for the collected fractions observed with SEM (Table I, column 6) show a difference with the desired particle-size ranges (column 2) for which the centrifuging times and speeds (columns 3 and 4 ) were esti-

Table I. Powder classification conditions and resulting particle and agglomerate sizes in the 15SLM suspensions used for film coating.

\begin{tabular}{|c|c|c|c|c|c|c|}
\hline \multirow{3}{*}{$\begin{array}{c}\text { Fraction/suspension } \\
\text { no. }\end{array}$} & \multirow{3}{*}{$\begin{array}{c}\text { Desired particle size } \\
\text { range } \\
(\mu \mathrm{m})\end{array}$} & $\begin{array}{l}\text { Stoke' } \\
\text { estime } \\
\text { centrift }\end{array}$ & $\begin{array}{l}\text { law } \\
\text { ed } \\
\text { ging }\end{array}$ & \multirow{3}{*}{$\begin{array}{l}\text { Weight of collected fraction } \\
(\mathrm{w} / \mathrm{o})\end{array}$} & \multicolumn{2}{|c|}{ SEM analysis } \\
\hline & & time/s & eed & & \multirow{2}{*}{$\begin{array}{c}\text { Observed } \\
\text { particle size range } \\
(\mu \mathrm{m})\end{array}$} & \multirow{2}{*}{$\begin{array}{l}\text { Agglomerates observed } \\
\underset{(\mu \mathrm{m})}{(\mu \mathrm{m})}\end{array}$} \\
\hline & & lower & upper & & & \\
\hline R1 & 2.0 & $3^{1 / 4} / 1000$ & & 24 & $0.2-0.5$ & 5 \\
\hline $\mathrm{R} 3$ & $1.1-1.5$ & $11^{1 / 4} / 1000$ & $6 / 1000$ & 21 & $0.15-0.40$ & 1.2 \\
\hline
\end{tabular}


mated. These times were in advance calculated with Eq. [1] for particles with diameter $d$ at the initial axial position $r_{0}$, which was taken as the upper level of the suspension in the tube. So in the estimated centrifuging time $t$ all particles with diameter $d$ or larger will settle. Smaller particles, which are initially already closer to the final axial position $r$ will also settle within this time. This causes the sediment always to contain a fraction of smaller particles. Based on weight this fraction is small $(\approx 20 \%)$, but based on the number of particles it can be rather large $(\approx 90 \%)(16)$. For the collected R1 fraction (see Table I) only a small number fraction $(<5 \%)$ of agglomerates (the largest being around $5 \mu \mathrm{m}$ ) were observed, but a very large number fraction of smaller particles in the range $0.2-0.5 \mu \mathrm{m}$ were observed. The big agglomerates, although small in number, constitute the larger weight fraction. The same holds for the R3 fraction, where a small number fraction of agglomerates/ particles up to $1.2 \mu \mathrm{m}$ in size was observed together with a large number fraction of smaller particles. The largest agglomerate/particle sizes observed with SEM in each fraction (Table I, column 7) are all within the desired particlesize ranges (column 2). The classification procedure resulted thus in powder fractions, all of which consisted of both a small number fraction of agglomerates/particles in the desired range and a large number fraction of smaller particles, which is, aside from the fraction of smaller particles, just what was aimed at.

Suspension preparation.-Suspensions of the perovskite-type materials were prepared by mixing the oxide powder with isopropyl alcohol (IPA). From sedimentation tests this was found to be a better suspending medium than (acidic) water. The mixture was agitated in an ultrasonic bath for 15-30 min in order to obtain good mixing and wetting of the powder. The stability of the suspensions was studied by means of a modified Andreasen pipette method (13). For this purpose dilute suspensions (1.5 w/o of solid) were prepared, with different amounts of stabilizing agent. Stable suspensions were obtained with the addition of $0.5-1.0 \mathrm{w} / \mathrm{o}$ (based on the solid) of the stabilizing agent.

Preliminary results of film coating experiments using suspensions containing different amounts of solid, showed that the better coatings were obtained with suspensions of $40 \mathrm{w} / \mathrm{o}$ of solid material. Because of the available amount of solid material and the minimum volume of the suspension needed for the film coating experiments no suspensions with higher solid contents were investigated.

The final suspensions used for the film coating experiments denoted R1, R3, and R5 were prepared from the collected fractions of the classified 15SLM powder (see Table I). These were suspended in isopropyl alcohol ( $40 \%$ of solid material by weight for the R1 and R3 fractions; 25 w/o for the R5 fraction) with 0.5 w/o addition of polyvinylpyrrolidone (PVP; Fluka, mean molecular weight $=10,000$ ) as stabilizing agent. Again ultrasonic agitation was used for complete mixing and wetting of the powder, this time with a Branson Sonifier $450(20 \mathrm{kHz} ; 30 \mathrm{~s}$ at $80 \mathrm{~W})$.

\section{Film Coating Process for Layer Deposition}

Substrate preparation.-Substrates used were dense circular disks (13 mm diam, $1 \mathrm{~mm}$ thick) of yttria-stabilized zirconia (YSZ) and dense alumina plates $(12 \times 6 \times 1 \mathrm{~mm})$. The YSZ substrates were prepared from commercial available powder (Zircar, ZYP-12.0; $\mathrm{ZrO}_{2}-12 \mathrm{w} / \mathrm{o}$ yttria). The powder was prepressed uniaxially at $50 \mathrm{kPa}$ to obtain rodshaped compacts, which were then iso-statically pressed at $400 \mathrm{MPa}$. These compacts were sintered at $1400^{\circ} \mathrm{C}$ for $3 \mathrm{~h}$. The final density was $>98 \%$ of the theoretical density. Disks were cut from the thus prepared rods. The alumina plates were cut from commercially obtained alumina rods (Haldenwanger, $\mathrm{Al}_{2} \mathrm{O}_{3}, 99.9 \%$ ).

Both kinds of substrates were polished single-sided with diamond paste down to a roughness value $R_{\mathrm{a}} \leq 0.05 \mu \mathrm{m}$. Prior to the layer deposition the substrates were ultrasonically cleaned in isopropyl-alcohol and degreased in boiling hexane.

Film coating procedure.-The substrates were mounted on a metal strip in order to obtain a coating on the polished surface only. The substrates were immersed in the 15SLM suspensions and withdrawn at a constant speed. Layer thicknesses obtained could be controlled by varying the withdrawal speed $(0.25-2.5 \mathrm{~mm} / \mathrm{s})$ and the number of repeated dips. In the latter case, the samples were dried in air between subsequent dips. Evaporation of the suspending medium was fast enough between subsequent dips.

After withdrawing the substrate from the suspension a small droplet always remains on the bottom side of the substrate, causing an increase in layer thickness at this side. This droplet-effect can be minimized by lowering the withdrawal speed. With the lowest withdrawal speed used $(0.25 \mathrm{~mm} / \mathrm{s})$ this leads to a small edge of not more than $0.5 \mathrm{~mm}$ on the substrate where an increased layer thickness can be observed. This droplet-effect will be even of minor importance when the surface area of the substrate is substantially increased.

Layer characterization.-After the film coating procedure the samples were heated at $1-2 \% \mathrm{~min}$ in air to a final temperature of $1100-1200^{\circ} \mathrm{C}$. In the first stage, decomposition of the stabilizing agent (PVP) adsorbed on the oxide particles had to occur. A TGA run was carried out to analyze this decomposition process. This TGA analysis confirmed the complete decomposition of the stabilizing agent PVP, when firing above $510^{\circ} \mathrm{C}$. In the second stage of the heating procedure initiation of the solid-state reaction between the 15SLM layer and the YSZ substrate is required to get a good adherence of the layer. According to the observations of Yamamoto et al. $(7,8)$ this reaction takes place around $1100^{\circ} \mathrm{C}$ for the manganese compound.

Preliminary experiments were performed. with nonclassified powders. These samples heated to $1100^{\circ} \mathrm{C}$ were mechanically unstable. The layers could be removed easily by scratching with a pair of tweezers. Considerable sintering of the layer had to occur also to give the layer a better mechanical stability. The dilatometer experiments showed that at a temperature of $1200^{\circ} \mathrm{C}$ sintering starts. Heating the samples in this preliminary series for $2 \mathrm{~h}$ at $1200^{\circ} \mathrm{C}$ in air was sufficient to give these layers the desired adherence and mechanical stability. When heated for $12 \mathrm{~h}$ or longer at $1200^{\circ} \mathrm{C}$ a solid-state reaction between 15SLM and $Y S Z$ took place.

For layers film coated from the classified fractions R1, R3, and R5 sufficient mechanical stability was achieved when heated at $1100^{\circ} \mathrm{C}$ for $2 \mathrm{~h}$. Furthermore these layers also showed good thermal stability. After heating for a prolonged time $(100 \mathrm{~h})$ at $1000^{\circ} \mathrm{C}$ no changes either in the layer thickness or in the morphology of the layer were observed. The narrowed particle-size distribution in these suspensions gives a better packing of the particles in the layer. This results in more contact points per volume unit, which in itself is already beneficial for a better mechanical stability.

In the Fig. 1-3 SEM photographs are shown of sintered layers film coated on YSZ from the suspensions R1, R3, and $\mathrm{R5}$, respectively. Remarkable differences were ob-

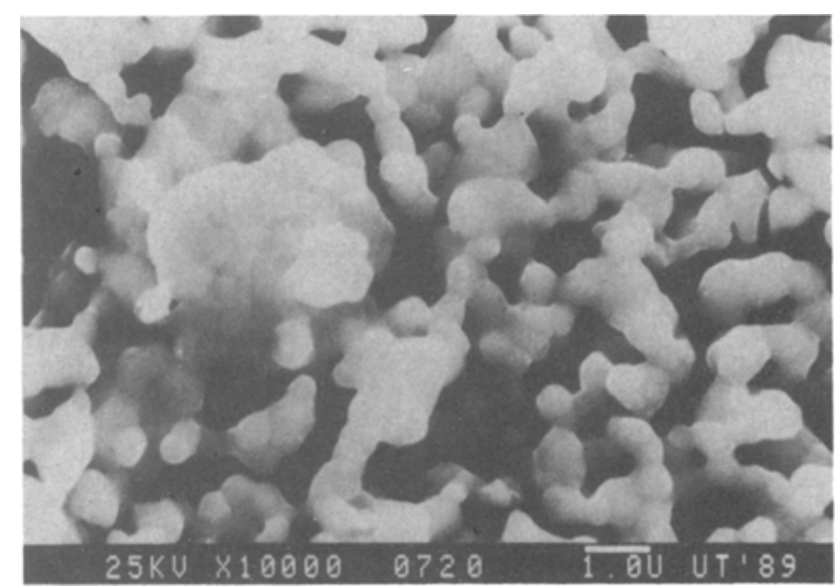

Fig. 1. SEM photograph of the 15SLM layer film coated from suspension $\mathbf{R} 1$. 


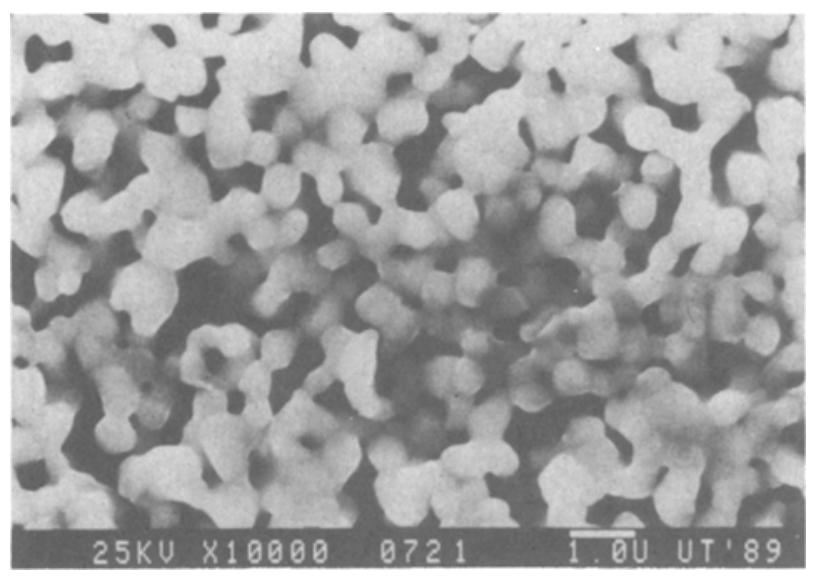

Fig. 2. SEM photograph of the 15SLM layer film coated from suspension R3.

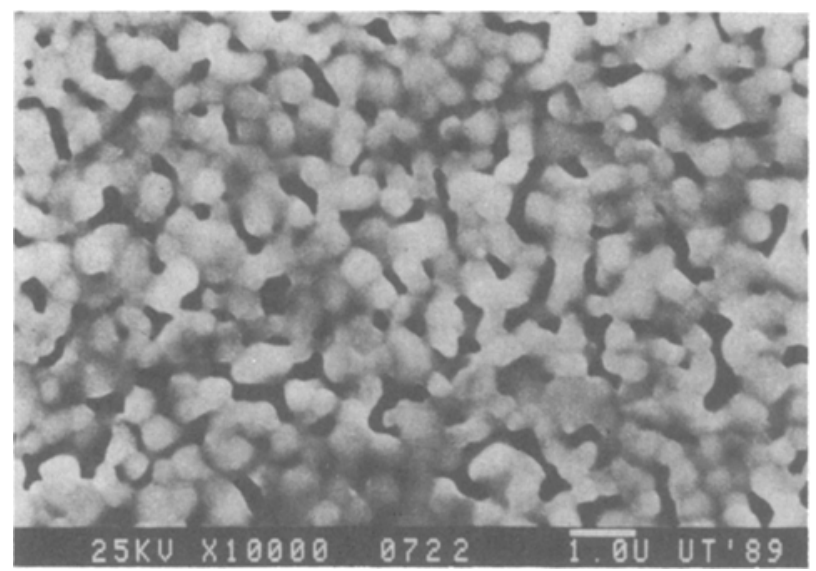

Fig. 3. SEM photograph of the I5SLM layer film coated from suspension R5.

served in the deposited layers. The layer film coated from R5 showed a close packed structure of only small grains sintered together. This layer had a very homogeneous porosity and pore-size distribution. Due to the slightly larger particles and relatively big agglomerates in the suspensions $R 3$ and $R 1$ pore-sizes and porosity increased remarkably in these layers. The large agglomerates in the suspension $\mathrm{R} 1$ caused the pore-size distribution in the layer to be less homogeneous.

Figure 4 shows a SEM photograph of a cross section of a film coated sample. It clearly shows the 15SLM layer on top of the dense YSZ substrate. The layer thickness is around $3.5 \mu \mathrm{m}$ and is very constant as is the porosity throughout the layer.

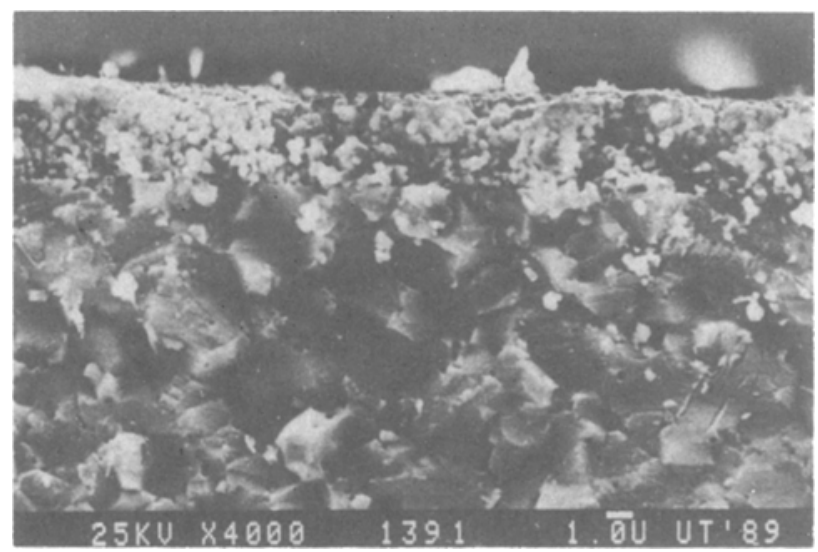

Fig. 4. SEM photograph of a cross-section of a film-coated 15SLM layer.
Layer thicknesses were determined using a DEKTAK surface probe. On several samples part of the film coated layer was removed from the substrate prior to heating them. The layer thickness was determined from the step height measured with the surface probe by scanning from the uncoated part of the sample to the coated part. Layer thicknesses ranged between 2.0 and $4.0( \pm 0.2) \mu \mathrm{m}$ for the layers film coated from the $R$ fractions on the alumina plates.

Large surface area deposition.-To demonstrate the feasibility of the film coating process for large surface areas, experiments were also performed with dense YSZ tapecast samples with the dimensions of $50 \times 50 \times 0.25 \mathrm{~mm}$.

A newly prepared suspension (25 w/o of solid material in isopropyl alcohol) of 15SLM powder, classified in the particle-size range from 0.2 to $1.0 \mu \mathrm{m}$, was used. The YSZ substrate was cleaned, degreased, and mounted on a metal support. The substrates were withdrawn from the suspension at a constant speed of $0.625 \mathrm{~mm} / \mathrm{s}$. To obtain a sample with a layer thickness of around $10 \mu \mathrm{m}$ the substrate had to be dipped 29 times. The coated substrate was heat-treated for $2 \mathrm{~h}$ at $1100^{\circ} \mathrm{C}$ in air. The surface of the film coated layer on top of the tape-cast YSZ substrate was observed.with SEM. A homogeneous coverage of the substrate with small grains in the particle size range from 0.2 to $1.0 \mu \mathrm{m}$ was observed, which agreed well with the classification step of the powder in suspension. No big agglomerates were observed. The layer thickness was $\approx 10 \mu \mathrm{m}$ and constant over the sample.

\section{Electrical and Electrochemical Properties}

Experimental.-Electrical resistivity measurements were performed on the perovskite-type layers film coated from the suspensions $R 1, R 3$, and R5 on alumina substrates in order to circumvent any contribution of the substrate to the conductivity. A four-point de technique with the four Pt point electrodes placed in one line was used. The two outer electrodes were the current carrying electrodes, and the two inner electrodes (placed $5 \mathrm{~mm}$ apart) were used as voltage probes. A BANK potentiostat Wenking LB $75 \mathrm{~L}$ connected to a Genesys XT microcomputer for data storage was used for conducting the measurements. Measurements were performed in a stream of oxygen.

Current-overvoltage measurements were performed on 15SLM layers with thicknesses of 5 and $10 \mu \mathrm{m}$ film coated from the suspensions R5 and R3 on dense YSZ substrates. A three-electrode configuration, as described in Ref. (17) was used. In the center of the sample a small circular shaped part (diameter $6 \mathrm{~mm}$ ) of the film-coated 15SLM layer was removed from the YSZ substrate. In this way the point-shaped reference electrode could be placed in the center of the sample in contact with the electrolyte. An annular-shaped current collecting $\mathrm{Pt}$ layer of $10 \mathrm{~mm}$ outer and $6 \mathrm{~mm}$ inner diameter was sputtered on the 15SLM layer to obtain good electrical contact with the Pt current leads. A similar annular-shaped Pt layer was sputtered on the opposite YSZ substrate side as counterelectrode. A spring-loaded $\mathrm{Pt}$ point contact electrode served as reference electrode. Measurements were performed using the Bank potentiostat Wenking LB $75 \mathrm{~L}$ or a Bank potentioscan Wenking POS 73 connected to a microcomputer for data storage and analysis. Two types of measuring programs were applied. The first one was a single-cycle voltammetry with scan rates of typically $2 \mathrm{mV} / \mathrm{min}$ to approach steady-state polarization conditions. The second program was a staircase cyclic voltammetry with steps of 25 or $50 \mathrm{mV}$. This step-scan started at $0 \mathrm{~V}$ polarization and cycled up and down the programmed voltage region, starting with the anodic branch, if included. AC impedance measurements were conducted using a Solartron FRA 1170. The current-voltage and ac impedance measurements were performed at $900^{\circ} \mathrm{C}$ in a constant stream of oxygen.

Conductivity measurements.-Figure 5 shows the specific conductivity (log $\sigma T$ ) as a function of the reciprocal temperature of the layers film coated on alumina from the suspensions R1, R3, and R5, respectively. Straight lines are 


\section{SLM on alumina}

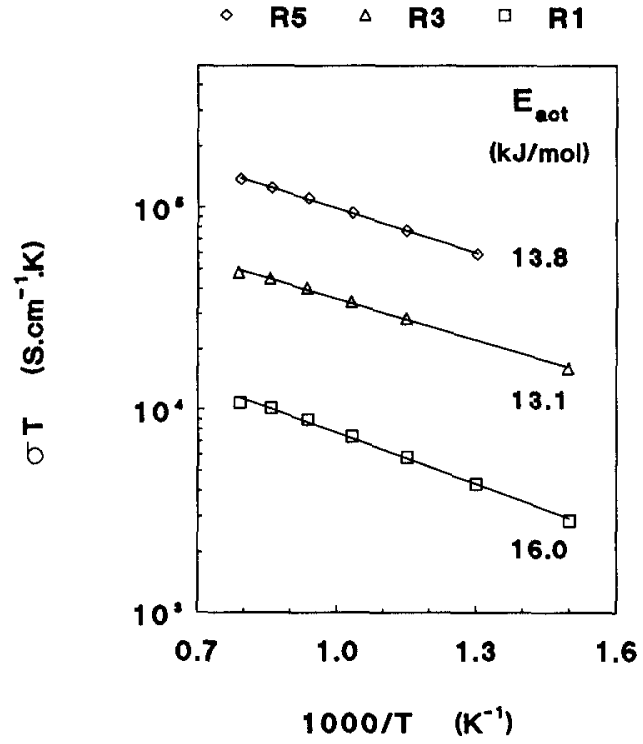

Fig. 5. Specific conductivities $(\log \sigma T)$ of the $15 S L M$ layers film coated from the suspensions $R 1, R 3$, and $R 5$, respectively, as a function of temperature $(1000 / T)$.

observed over the whole temperature range, which is consistent with a small-polaron conduction mechanism model (18).

Activation energies calculated from the slopes are $16.0 \mathrm{~kJ} / \mathrm{mol}$ for the R1 sample, $13.1 \mathrm{~kJ} / \mathrm{mol}$ (R3 sample), and $13.8 \mathrm{~kJ} / \mathrm{mol}$ ( $R 5$ sample). These values are all slightly higher than the value of $9.6 \mathrm{~kJ} / \mathrm{mol}$ reported by Kertesz et al. (19) for ceramic samples with the composition $\mathrm{Sr}_{0.16} \mathrm{La}_{0.84} \mathrm{MnO}_{3}$, having an apparent density of $80 \%$.

Specific conductivity values for the R5 sample are oneorder of magnitude higher than the ones measured for the R1 sample. The specific conductivity of the R3 sample lies in between the latter two. These results show the effect of the number of contact points (packing density) in the porous layer on the specific conductivity. The R5 sample has the smallest grain size and obviously the largest number of contact points per volume-unit together with the smallest mean pore-size (see Fig. 1-3). Porosity values of the film coated layers are not yet known, but the SEM photographs indicate values greater than $40 \%$. So for all our samples the packing density is much smaller than for the samples reported by Kertesz et al. (19). Concentration polarization of the charge carriers at the contact points may account for the higher values of the activation energy, that was observed in the porous layers.

The specific conductivity of the R5 sample amounts to $109 \mathrm{~S} \cdot \mathrm{cm}^{-1}$ at $1000^{\circ} \mathrm{C}$, which is adequate for a planar type SOFC. The value mentioned is also rather close to the value of $133 \mathrm{~S} \cdot \mathrm{cm}^{-1}$ reported by Kertesz et al. (19) for the conductivity of the $80 \%$ dense sintered sample.

Current-voltage behavior.-Figure 6 shows four singlecycle voltammetry scans (cathodically from -800 to $0 \mathrm{mV}$ ) for the sample R5 $(5.1 \mu \mathrm{m})$ measured subsequently within a period of two weeks. During this period the sample was kept at $897^{\circ} \mathrm{C}$ in a stream of oxygen. When no measurements were being performed the sample was kept at zero polarization. Figure 6 shows, that all subsequent measurements led to a set of very reproducible current-voltage curves. An identical curve was obtained, when staircase cyclic voltammetry was applied to the sample. The current remained constant when a constant maximum applied polarization of $-800 \mathrm{mV}$ was applied over an observation period of $20 \mathrm{~h}$. No degradation of the sample was observed during subsequent scans. After removing the sample from the measuring cell, the perovskite layer appeared to be completely intact and well attached to the electrolyte substrate. Reproducible current-voltage curves were obtained also for the samples R5 $(10.1 \mu \mathrm{m})$ and R3 $(5.2 \mu \mathrm{m})$, respec-
15SLM (R5 - $5.1 \mu \mathrm{m}) / \mathrm{ZY} 13 / \mathrm{Pt}$ $897{ }^{\circ} \mathrm{C} /$ oxygen

$\circ$ day $1 \quad \Delta \quad$ day $2 \quad \nabla \quad$ day $7 \quad \square \quad$ day 9

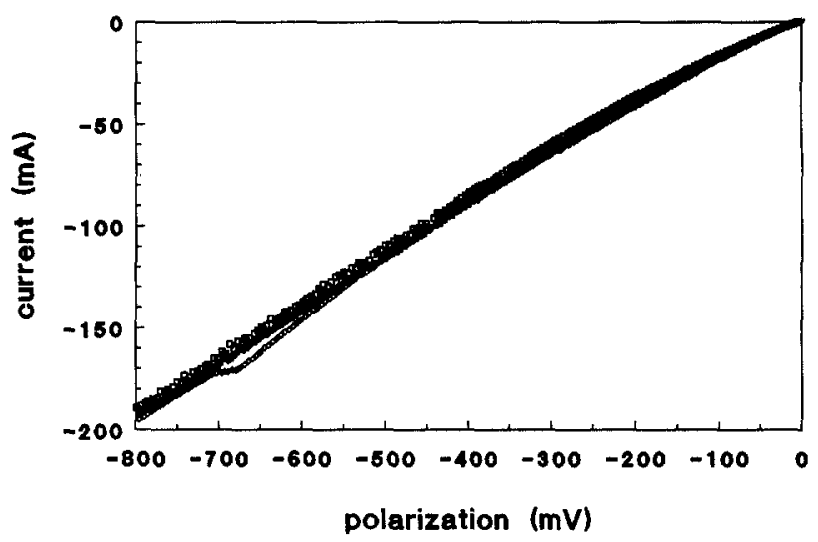

Fig. 6. Three-electrode current-voltage measurements (cathodic only) for $15 \mathrm{SLM}(\mathrm{R} 5-5.1 \mu \mathrm{m}) / \mathrm{YSZ} / \mathrm{Pt}$ at $897^{\circ} \mathrm{C}$ in oxygen.

tively, when cathodic polarization was applied under the same conditions.

Figure 7 shows the potential drop $\left(I . R_{u}\right)$ corrected current-overvoltage curves for the samples R5 $(5.1 \mu \mathrm{m})$, R5 $(10.1 \mu \mathrm{m})$, and R3 $(5.2 \mu \mathrm{m})$, respectively (the uncorrected curve for the sample R5 $(5.1 \mu \mathrm{m})$ is given in Fig. 6). The value of $R_{\mathrm{v}}(R$-unknown is the resistance of the electrolyte area between the reference and the perovskite electrode) was determined from the high-frequency extrapolation of the ac impedance plot taken between reference and perovskite electrode. The corrected current-overvoltage curves for the three samples differ only in a limited way, except for the region at very high current densities $\left(>0.1 \mathrm{~A} / \mathrm{cm}^{2}\right)$. This difference is caused by the magnitude of the $I . R_{\mathrm{u}}$ correction term at high current densities.

Hammouche et al. (20) observed a sharp increase in the current under high cathodic polarization for Sr-doped $\mathrm{LaMnO}_{3}$ electrodes. This was ascribed to the reduction of the electrode material. Oxygen ion vacancies were created and the electrode is no longer mainly an electronic conductor, but mixed conductivity had been generated. This means that the oxygen reduction reaction is no longer confined to occur at the electrode/electrolyte/gas-phase three-
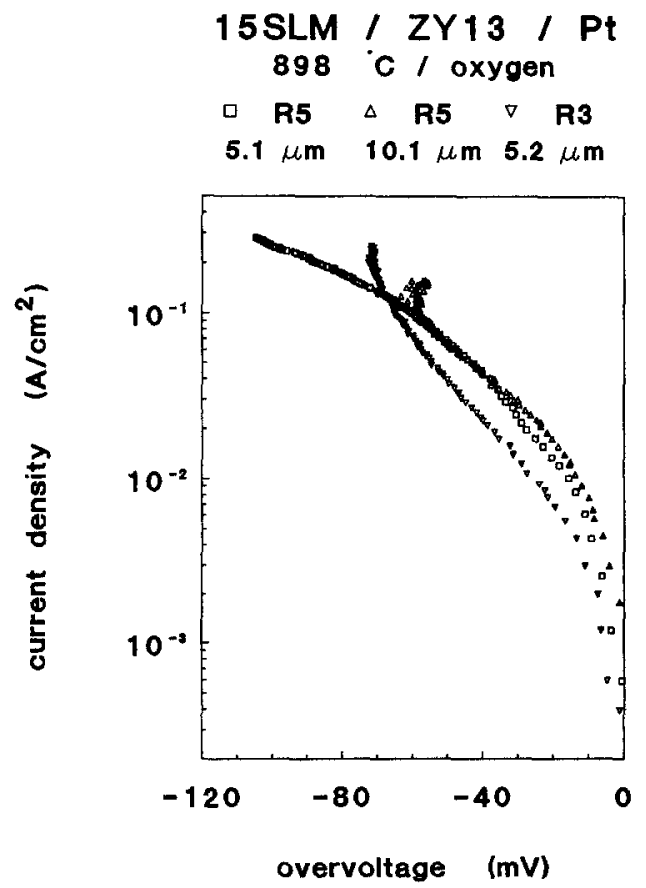

Fig. 7. Tafel plot, corrected for $I \cdot R_{\mathrm{u}}$ of the current-overvoltage curves measured for the systems $15 \mathrm{SLM} / \mathrm{YSZ} / \mathrm{Pt}$ at $898^{\circ} \mathrm{C}$ in oxygen. 
phase boundary line. The surface of the now mixed conducting manganite electrode near the electrode/electrolyte interface offers a new oxygen reduction pathway (20). Hammouche et al. (20) reported this transition to occur at overvoltages of -160 and $-158 \mathrm{mV}$ for the compositions $\mathrm{Sr}_{0.1} \mathrm{La}_{0.9} \mathrm{MnO}_{3}$ and $\mathrm{Sr}_{0.19} \mathrm{La}_{0.81} \mathrm{MnO}_{3}$, respectively, in air at $960^{\circ} \mathrm{C}$. In Fig. 7 it can be observed that these high overvoltages are not reached in the measurements performed here for the composition $\mathrm{Sr}_{0.15} \mathrm{La}_{0.85} \mathrm{MnO}_{3}$ in oxygen at $900^{\circ} \mathrm{C}$. With these conditions the overvoltage where the transition occurs, would possibly be even higher. Therefore any enhancement of the current at high overvoltages is very unlikely to be caused by the reduction of the cathode material.

Figure 7 shows no significant dependence of the overvoltage on the layer thickness nor on the morphology of the porous layers. Yamamoto et al. (7), however, did find a dependence of the overvoltage on the layer thickness (in the range $1.4 \mu \mathrm{m}$ ) for $\mathrm{Sr}$-doped $\mathrm{LaMnO}_{3}$ layers deposited on the YSZ electrolyte by RF sputtering. These sputtered layers were quite dense, with very inhomogeneously distributed large $(1 \mu \mathrm{m})$ pores and even cracks in the thicker $(3.2 \mu \mathrm{m})$ layers. According to Yamamoto et al. the observed dependence of the overvoltage on the layer thickness is caused by a hampering of the direct access of oxygen to the electrolyte/electrode interface in the thicker dense sputtered layers (7).

The highest current densities observed here in the measurements performed on the film coated 15SLM/YSZ halfcell systems were $0.5 \mathrm{~A} / \mathrm{cm}^{2}\left(5000 \mathrm{~A} / \mathrm{m}^{2}\right)$. Such values are quite adequate for $\mathrm{SOFC}$ application. At a current density of $0.1 \mathrm{~A} / \mathrm{cm}^{2}$ the observed overvoltage is $60-70 \mathrm{mV}$ for all three samples (see Fig. 7). These values are considerably lower than the value of $300 \mathrm{mV}$ at a current density of $0.01 \mathrm{~A} / \mathrm{cm}^{2}$ reported by Takeda et al. (8) for the composition $\mathrm{Sr}_{0.1} \mathrm{La}_{0.9} \mathrm{MnO}_{3}$. However, Takeda et al. (8) reported a value of $55 \mathrm{mV}$ at a current density of $0.1 \mathrm{~A} / \mathrm{cm}^{2}$ for the composition $\mathrm{Sr}_{0.5} \mathrm{La}_{0.5} \mathrm{MnO}_{3}$, which showed the lowest overvoltages of all compositions of the $\mathrm{Mn}$-perovskites in vestigated by these authors. Hammouche et al. $(11,20)$ too have reported, that the composition $\mathrm{Sr}_{0.5} \mathrm{La}_{0.5} \mathrm{MnO}_{3}$ had the lowest overvoltages. This is attributed to the mixed-conductivity occurring in these perovskites with high Sr-doping levels, which increases the electrocatalytic activity, i.e., enhances the oxygen transfer.

The disadvantage of the Mn-perovskites with high $\mathrm{Sr}$ contents $(>0.2)$ is however, the increased reactivity with the YSZ electrolyte at the operating temperature $\left(1000^{\circ} \mathrm{C}\right)$ of the SOFC (19). The results reported here for the film coated 15SLM layers, show that it is possible to lower the cathodic overvoltages for the oxygen reduction reaction by improving the microstructure of the ceramic electrode layer. Furthermore the advantage of maintaining a reduced reactivity with the YSZ electrolyte is preserved by keeping the Sr content low.

\section{Conclusions}

The film coating procedure described in this paper is a suitable technique for the reproducible production of thin porous ceramic electrode layers of equal thickness with well-defined microstructure and morphology on dense (e.g., YSZ) substrates. The microstructure of the film coated layer is determined by the particle-size distribution in the suspension which in turn depends largely upon the powder synthesis and the classification of the powder. A very narrow particle-size distribution in suspension yields a very homogeneous close packed layer with a very narrow pore-size distribution. It is shown that the procedure is applicable for large surface areas.

The electrical conductivity of the film coated perovskitetype $\mathrm{Sr}_{0.15} \mathrm{La}_{0.85} \mathrm{MnO}_{3}$ (15SLM) layer depends largely on the microstructure of the porous layer. For the close-packed homogeneous layer film coated from the suspensions with the most narrow particle size distribution (R5), a specific conductivity of $109 \mathrm{~S} \cdot \mathrm{cm}^{-1}$ was obtained at $1000^{\circ} \mathrm{C}$. This value is adequate for application in a planar type of SOFC.

For the system 15SLM/YSZ/Pt oxygen pumping current densities of up to $0.5 \mathrm{~A} / \mathrm{cm}^{2}$ were reached. Only a limited influence of the layer thickness and the microstructure of the film coated 15SLM layers on the current-overvoltage behavior were observed. The overvoltages measured at a current density of $0.1 \mathrm{~A} / \mathrm{cm}^{2}$ are low $(60-70 \mathrm{mV})$.

In comparison with the literature, it is shown that it is possible to lower the cathodic overvoltages for the oxygen reduction reaction by improving the microstructure through film coating of the ceramic electrode layer. Furthermore the advantage of maintaining a reduced reactivity with the YSZ electrolyte is preserved by keeping the $\mathrm{Sr}$ content low. This is of importance for the application of thin porous ceramic electrode layers in SOFC.

\section{Acknowledgments}

The investigations were performed under contract with the Commission of the European Communities (CEC) within the Non-Nuclear Energy R and D Programme (Contracts No. EN3E-167-E and EN3E-168-P).

Manuscript submitted April 26, 1990; revised manuscript received Jan. 19, 1991. This was Paper 552 presented at the Hollywood, FL, Meeting of the Society, Oct. 15-20, 1989 .

The University of Twente assisted in meeting the publication costs of this article.

\section{REFERENCES}

1. E. Bauer and H. Preis, Z. Elektrochem, 43, 727 (1937).

2. B. C. H. Steele, "Ceramic Electrochemical Reactors (CER)-Current Status and Applications," Ceramionics, Surrey, England (1987).

3. J. T. Brown, Energy, 11, 209 (1986).

4. E. F. Sverdrup, C. J. Warde, and A. D. Glasser, in "From Electrocatalysis to Fuel Cells," G. Sandstede, Editor, p. 255, Univ. of Washington Press, Seattle (1972).

5. C. C. McPheeters, D. W. Dees, S. E. Dorris, and J. J. Picciolo, in "1988 Fuel Cell Seminar Abstracts," p. 29, Long Beach, CA, Oct. 23-26, 1988.

6. M. Hsu, ibid., p. 33 .

7. O. Yamamoto, Y. Takeda, Y. Tomida, and M. Noda, Solid State Ionics, 22, 241 (1987).

8. Y. Takeda, R. Kanno, M. Noda, Y. Tomida, and O. Yamamoto, This Journal, 134, 2656 (1987).

9. L. G. J. de Haart, R. A. Kuipers, K. J. de Vries, and A. J. Burggraaf, in "Proceedings of the First International Symposium on Solid Oxide Fuel Cells," S. C. Singhal, Editor, PV 89-11, p. 197, The Electrochemical Society, Inc., Pennington, NJ (1989).

10. M. A. C. G. van de Graaf, T. van Dijk, M. A. de Jong, and A.J. Burggraaf, Sci. Ceramics, 9, 75 (1977) D. H. A. Blank, H. Kruidhof, and J. Flokstra, J. Phys. D: Appl. Phys., 21, 226 (1988).

11. A. Hammouche, E. Siebert, and A. Hammou, Mater. Res. Bull, 24, 367 (1989).

12. H. Ohbayashi, 'T. Kudo, and T. Gejo, Jpn. J. Appl. Phys., 13, 1 (1974).

13. S. Ross and I. D. Morrison, "Colloidal Systems and Interfaces," Chap. I.D., p. 47, John Wiley \& Sons, Inc., New York (1988).

14. Th. F. Tadros, in "Solid/Liquid Dispersions," Th. F. Tadros, Editor, Chap. 11, p. 226, Academic Press, Ltd., London (1987).

15. "Handbook of Chemistry and Physics," 57th ed., R. C. Weast, Editor, CRC Press, Cleveland, OH (1977).

16. M. Parish and H. K. Bowen, Ceramics Int., 10, 75 (1984),

17. B. A. Boukamp, I. C. Vinke, K. Seshan, K. J. de Vries and A. J. Burggraaf, Solid State Ionics, 28-30, 1187 (1988); I. C. Vinke, K. Seshan, B. A. Boukamp, K. J. de Vries, and A. J. Burggraaf, ibid., 28-30, 1201 (1988).

18. J. B. Goodenough, in "Progress in Solid State Chemistry," Vol. 5, H. Reiss, Editor, p. 145, Pergamon Press, Ltd., Oxford (1971); G. H. Jonker and S. van Houten, in "Halbleiterprobleme," Band VI, F. Sauter, Editor, p. 118, Vieweg, Braunschweig (1961).

19. M. Kertesz, I. Riess, D. S. Tannhauser, R. Langpape, and F. J. Rohr, J. Solid State Chem., 42, 125 (1982).

20. A. Hammouche, E. Siebert, M. Kleitz, and A. Hammou, in "Proceedings of the First International Symposium on Solid Oxide Fuel Cells," S. C. Singhal, Edi tor, PV 89-11, p. 265, The Electrochemical Society Inc., Pennington, NJ (1989). 